\title{
40 years on. Has the vision of Alma-Ata been realized?
}

\author{
40 anos depois. A visão de Alma-Ata foi \\ concretizada?
}

\author{
Después de 40 años. ¿Se ha hecho realidad \\ la visión de Alma-Ata?
}

Martin Roland 1

doi: $10.1590 / 0102-311 \times 00212218$

In this issue of Cadernos de Saúde Pública, four articles describe the state of primary care in Portugal 1, Brazil 2, Canada ${ }^{3}$ and Chile 4 . These papers are timely in view of the 40th anniversary of the 1978 AlmaAta Declaration 5. This landmark declaration in the history of primary care asserted that "All governments should formulate national policies, to launch and sustain primary health care as part of a comprehensive national health system", defining universal access to primary care as "the central function and main focus of a country's health system". Against this challenge, how has healthcare in these countries fared?

Portugal moved from a system entirely based on private practice to a National Health System in 1979 with increased access to care and improvements in health indicators such as infant and maternal mortality and life expectancy, which the authors describe as "dramatic". Residency programmes in primary care were created in the 1990s, with most primary care physicians working in the public sector and universal coverage for the population. Since then, primary care has become organized into autonomous teams of physicians, nurses and administrators (Family Health Units), described by the authors as a "veritable utopia" for primary care. None of these reforms were established without considerable opposition from entrenched interests, but primary care is identified as one of the stabilizing factors in Portugal, given the country's more recent economic problems.

Brazil embarked on equally dramatic reforms in 1990 with the creation of a Brazilian Unified National Health System (SUS), guaranteeing universal access to care, and the creation of Family Health Teams that now cover $90 \%$ of the population. These geographically defined teams typically have a family physician and nurses with oral health teams and other disciplines in the larger ones. Community health agents form an important part of these teams, with members drawn from the local community and so particularly well placed to understand the needs of their communities and to provide appropriate health promotion advice. The country has problems to provide enough primary care physicians, and the demand on providing populations with health teams remain high. Indeed, the vision of primary care as a coordinating force is described by the authors as a "distant reality". Nevertheless, the achievement of Brazil in providing a universal model of primary care in a large country with very diverse needs is impressive. More recent problems, also experienced by many other countries, are the entry of the corporate private providers reducing the number of physicians available to work in the public sector, allied to austerity programmes implemented by the central government. A feature of the Brazilian healthcare and the model in several Scandinavian countries is the involvement of municipalities playing a strong role in the finance and delivery of healthcare.
1 University of Cambridge, Cambridge, U.K.

Correspondence

M. Roland University of Cambridge. 44 Sedley Taylor Road, Cambridge/CambridgeshireCB2 8PN, U.K.

mr108@cam.ac.uk 
Canada's "universal coverage" is less universal than that of Brazil as it does not generally cover dental care, outpatient medication or nonmedical health professionals. Furthermore, each province in Canada has its own health system. Nevertheless, Canada represents a model of healthcare in which publicly funded family medicine has been established as the basis of the healthcare system for many years. Canada, just as many countries with areas of very low population density, has difficulty in providing medical staffing for these very rural areas, and nurses and nurse practitioners make up an important part of the primary care workforce.

Chile has had "zone-based" general practitioners since the 1950s but for many doctors this merely served as a route towards specialist training. A national focus on developing primary care started in 2003 with the development of family health centers, guaranting access to a priority set of health problems and to the first specific training programmes for family physicians. However, this was poorly coordinated, and family medicine was not formally recognized as a medical speciality until 2014.

So what have these countries done well, and what did they struggle at? All represent substantial steps along the road to the World Health Organization (WHO) objective of universal healthcare coverage based on primary medical care. Some, such as Canada, have primary care systems that have matured over several decades whereas others face the challenge that many countries face of moving to a more primary care-based system without an established cadre of primary care physicians. Sometimes, as in China, this means wholesale reallocation of existing specialists to work in primary care that may be unpopular both with patients who perceive the doctors to be undertrained and with the physicians themselves who lose some of the financial benefits of specialist practice. Indeed, China is an example of a country where the very rapid implementation of a new national programme has left primary care centers lacking in both training and equipment 6,7 .

Despite these shortcomings, tremendous progress has occurred since the Alma-Ata Declaration 40 years ago, amply demonstrated by the four countries described in this issue. Despite this, they all face significant problems, the commonest of which is the difficulty in the coordination of care between different health sectors and between health and social care. This is an area that most countries struggle with, often because of poor exchange of information (very few countries have a universal electronic record covering primary and secondary care), different funding arrangements for different sectors, and different working cultures in health and social care. These problems are becoming more important as the populations of both developed and developing countries age, with patients who have multiple medical problems being increasingly dependent on comprehensive well-coordinated care.

Do any of these countries live up to the vision of Alma-Ata? Here the answer is "no". The original declaration was radical in several ways. First, in the assertion that "Health is a state of complete physical, mental and social wellbeing, and not merely the absence of disease or infirmity, and is a fundamental human right", and second, in the very broad assertion that "Primary health care involves, in addition to the health sector, all related sectors and aspects of national and community development, in particular agriculture, animal husbandry, food, industry, education, housing, and public works" 5 . No country comes close to meeting this second vision being very focused on medical care and, indeed, concerns were expressed that the Alma-Ata declaration was unrealistic from the very beginning. In 1979, the Rockefeller Foundation funded a conference in Bellagio, Italy, which produced the idea of Selective Primary Care more focused on low income countries and a narrowly defined set of objectives relating to growth monitoring, oral rehydration, breast feeding and immunization (“GOBI”). These objectives were subsequently expanded to include food supplementation, female literacy and family planning ("GOBI-FFF"). These aims were clearly a long way from the Alma-Ata vision of comprehensive primary care, though they were easier to measure and potentially easier to fund as donors were generally more interested in short-term technical projects with clear budgets rather than in broadly defined health programs. The development of primary care was also opposed by many doctors in developing countries not least because primary care was less financially rewarding than specialist practice.

So where are we now? Although the original vision of Alma-Ata is far from achieved, the beliefs that universal healthcare coverage (UHC) is an important part of any healthcare system and that such coverage should be founded on strong medical primary care is widely accepted in both developed and developing countries. However, not all governments (notably the US) would agree with one of the paragraphs of the original declaration, which asserted that "Governments have a responsibility for the health of their people who can be fulfilled only by the provision of adequate health and social measures" 5 
To mark the 40th anniversary of the Alma-Ata Declaration, the WHO met again in Kazakhstan on 25th-26th October 2018 and produced a revised declaration 8. This declaration reaffirms that "health is a state of complete physical, mental, and social well-being, and not merely the absence of disease or infirmity and is a fundamental human right". The revised declaration also reiterates the need for reducing inequalities in health, especially that between developing and developed countries. However, the vision on primary care that goes well beyond primary medical care is largely gone and the acknowledgement that progress depends on what a country can afford exists. One important but rarely enacted point made in the original declaration is reiterated, namely that greatly improved health could be attained through a fuller and better use of the world's resources, "a considerable part of which is now spent on armaments and military conflicts".

So, Alma-Ata is far from dead. In fact, its influence has been far-reaching with many countries now seeking a healthcare system based on universal access to primary care. Although not in every country, the acknowledgement of the role of the state as both funder and coordinator of the healthcare system and hence of primary care is increasing, though integration of different parts of the system remains a near-universal challenge. The restatement of the declaration in 2018, 40 years on, has lost few of the key points in the original declaration and, indeed, it is now more likely to be seen as widely applicable to both developed and developing countries than it was 40 years ago.

1. Biscaia AR, Fehn AC, Pereira A. The Portuguese family physician: a narrative. Cad Saúde Pública 2019; 35:e00127118.

2. Coelho Neto GC, Antunes VH, Oliveira A. The practice of Family and Community Medicine in Brazil: context and perspectives. Cad Saúde Pública 2019; 35:e00170917.

3. Brandão JRM. Primary health care in Canada: current reality and challenges. Cad Saúde Pública 2019; 35:e0178217.

4. Romero AML. Family medicine in Chile: challenges for professional practice. Cad Saúde Pública 2019; 35:e00172417.

5. World Health Organization. Declaration of Alma-Ata. International Conference on Primary Health Care, Alma-Ata, USSR, September 1978. http://www.who.int/publications/ almaata_declaration_en.pdf (accessed on Nov/2018).
6. Li X, Lu J, Hu S, Cheng KK, De Maeseneer J, Meng Q, et al. The primary health-care system in China. Lancet 2017; 390:2584-94.

7. Wong WCW, Jiang S, Ong JJ, Peng M, Wan E, Zhu S, et al. Bridging the gaps between patients and primary care in China: a nationwide representative survey. Ann Fam Med 2017; 15:237-45.

8. World Health Organization. Declaration on primary health care, Astana 2018. http://www. who.int/primary-health/conference-phc/dec laration (accessed on Nov/2018). 